\title{
The Cell-Life Project: Converging technologies in the context of HIVIAIDS
}

\author{
ULRIKE RIVETt AND Jonathan TAPson
}

$\mathrm{T}$ he last decade has seen great strides in our understanding of the impact and complexity of HIV / AIDS. From battles fought in court to provide free treatment for HIV positive mothers and to reduce drug prices (Mbali 2003; Barnard 2002) to the complexity of managing the supply of medication to the most rural areas (Wood et al. 2008), South Africa has become the country known not only for its high prevalence rate, but also for its ambitious target of treating $80 \%$ of all people requiring anti-retrovirals (ARVs) by 2011 (DOH 2007).

Throughout the last few years, one aspect of treatment has remained an intractable challenge and concern for all parties involved. Successful and sustainable treatment with ARVs requires an adherence rate of $95 \%$ to prevent the development of drug resistance and the mutation of the virus. Additionally, the treatment requires a complex time-and-diet regime, and side effects need to be monitored regularly. (Bekker et al. 2003) 
The provision of medication and compliance to it is often complicated by poverty, distance to medical facilities, and an underdeveloped health care system (Nattrass 2006).

A number of NGO and civil society initiatives were launched from 2000 onwards to investigate methods to support patients in impoverished areas. Despite limited resources, some of these initiatives have been successful for several years now, by using creative ways to increase manpower and support.

One of these successful projects was launched in 2001 in Gugulethu, a high-density, low-income township outside of Cape Town. The Desmond Tutu HIV Centre (DTHC) of UCT had developed a treatment management method that used HIV-positive community members who had successfully started their antiretroviral treatment (ART) programme as treatment advocates. After receiving training for peer-counselling and adherence to medication, these 'therapeutic counsellors' became the main support systems for patients who had started ART. Each of these counsellors was responsible for between 15-20 patients. By visiting patients regularly and engaging with them, issues such as diet problems, side effects and financial and social challenges, were identified 'remotely' the patient was not required to come to the clinic and the human resource of doctors and nurses was extended through the counsellors. However, once patient numbers grew, follow-up and record keeping became a challenge (Bekker et al. 2003).

In 2001, Cell-Life was started as an initiative between academics in the Engineering Faculties of the University of Cape Town (UCT) and Cape Peninsula University of Technology (CPUT) to investigate the possibilities of developing technological tools that would support medical staff in managing ARV treatment more effectively. Being aware of the unsuitability of electronic patient systems due to the low penetration of computers and the limited access to the internet, cellular (mobile telephone) technology was identified as a viable option for data collection and information management. Engagement with colleagues from the medical sector and the DTHC highlighted that successful and sustainable treatment does not only rely on reminding a patient to take medication, but on a more comprehensive support structure to assist patients remotely, so that HIV / AIDS can be managed similarly to other chronic conditions. 


\section{THE TECHNOLOGY}

Supporting medical staff in ensuring high adherence rates of patients was the main goal of the first technology development of the CellLife team. Since ARV treatment is a lifelong programme for the patient and the medical staff involved, it is important to develop a solution that offers sustainability through increasing the capacity and resourcing of medical staff. This is particularly so given the extent of the HIV / AIDS epidemic in South Africa, which requires complex treatment of a chronic and permanent condition for an enormous number of people, thereby making medical staff and infrastructure a major constraint on a successful outcome.

The hypothesis of Cell-Life was that by developing an appropriate tool which supports clinical staff in decision making, by providing information that is relevant and up-to-date, patients will receive improved care. It was also hoped that such a system could increase organizational efficiency, which would ultimately lead to extending treatment programmes to more HIV+ people.

Cell-Life focused on supporting under-resourced public health centres that faced the following challenges:

- high HIV prevalence rate within the service area

- low income levels

- high staff turnover in the health centre

- lack of infrastructure

- lack of experience with computers or information systems

- limited financial resources

- challenges within the clinical management structures and processes

Often these types of clinics or health centres are based in peri-urban and rural environments, where access to treatment is defined by the complexity and cost of travelling to the clinic (Nattrass 2006).

Based on the knowledge gained through failed information system projects in the developing world, particularly in government sectors (Heeks 2003), Cell-Life identified that a new approach to the understanding and development of information management within resource constrained settings was required. Most of the failed projects showed that top-down, functionalist models (Hirschheim \& Klein 1989) based on acquisition by management 
resulted in a development-as-modernisation approach (Moodley 2005; Gurumurthy \& Singh 2009). Fundamentally, the systems were developed by technologists and provided to a passive user. The development process was separated from the context and the users' experience, which subsequently often resulted in project failure.

A process of matching the information needs of stakeholders with the technologies known to staff and their patient management approach was used to identify the most appropriate technology for the context of each environment (rather than developing a 'onesize-fits-all' system). The concept of integrating information system design, user analysis and development was adapted by Cell-Life from the totalising approach of identifying the 'average user', and became instead an approach that focused on the information and the technology available within each community. This lead to a paradigm shift within the system design thinking of the Cell-Life team from an attitude of extracting information from the user, to an engaging attitude that resulted in benefits to the medical staff and subsequently the patient.

Cell-Life concentrated on identifying the most important data and information that was required to be communicated, and then identified available technologies that would suit the local context, appreciating the variety of needs and realities of each clinic.

One such technology in use in a number of under-resourced environments was the cellphone. By early 2000, South Africa, like many other developing countries, was already starting to see a dramatic increase in the use of cellular technologies. In 2005, it was estimated that South Africa had in excess of 20 million cellphone users, out of a total population of 46.9 million (see: $\underline{\text { htp: }: / / ~}$ www.statssa.gov.za). South Africa's usage rate was at $43 \%$ of the population, which was comparable to a developed country like France where the usage was approximately $42 \%$. An article on Cellular Online from the publication African Telecommunication Indicators 2004, entitled 'Does mobile technology hold the key to widening access to ICTs in Africa?', bases the reasons for the success of cellular technology in Africa, and its effect on access to ICTs, upon the lack of communications infrastructure and the high demand due to unmet need (ITU 2004; for full article, see: http: / / www.cellular. co.za/news 2004/may/0501004-itu says africa is the world.htm) 
Beyond its primary function for basic oral communication, the main advantage of the cellphone lies in its ability to transfer data using a variety of technologies. By 2003, technologies such as WIG (Wireless Internet Gateway), which use a simple SMS structure, were well developed. Today, a number of technologies, from USSD (Unstructured Supplementary Services Data) to Java applications on high end phones, have resulted in cellphones becoming a key tool for data collection in the field (UN 2008).

In the context of implementing information management systems in the primary health care sector, cellular technology had the added advantage that it was a known and widely-used product, and therefore one of the major concerns of technology implementation and uptake in under-resourced areas was minimised (Fynn et al. 2006).

The first Cell-Life application, 'Adherence', was a simple WIG menu that was loaded onto the cellphones of therapeutic counsellors and treatment managers of the Desmond Tutu HIV Centre. The cellphone was used to collect information that had previously been written down in a book and then carried back to the hospital. There were a number of obvious challenges with the paper system, such as the records not being available in the patient folder, the books occasionally getting lost, and there was no possibility of immediately addressing issues in the field, as information was not available until the books were returned to the Centre.

The Adherence cellphone application enabled the therapeutic counsellors to collect medical and socio-economic data at the homes of patients, and to then send the information to the clinic via the GSM network. The data were received in real-time in a centralised database, and clinical staff were able to review entries and collate information. (Skinner et al. 2007; Natrass et al. 2007)

Sister Lulu Mtwisha of the Desmond Tutu HIV Centre describes the old paper-based system in comparison to the electronic system:

It is incomparable, the paperwork was good for that particular period, but with the advent of Cell-Life it is something that I don't wish to revisit. With the old system I would get the information a week after everything had happened. I would make the counsellors hand in the paperwork of their visits for the past week on a Monday or Tuesday. I would then 
bring the pile of forms back to my office at Desmond and only when I had time would I peruse and check. I may not have noticed anything going wrong for an entire month and only at the end of the month when I could look at the data for that whole month, would I notice that a certain patient had not been visited. Now with the Cell-Life system I can pick this up quickly and there is really nothing that can fall off the plate without me noticing. The system allows me to prevent situations from happening rather than having to fix a situation once it has already happened. It's a form of damage control. (Interview, 30 June 2005)

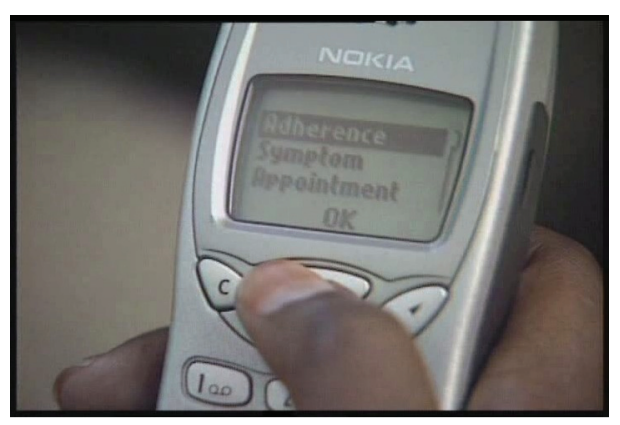

Figure 1: A typical menu from the WIG interface in the original 'Adherence' application, shown in use on a basic cellphone

Cell-Life has developed a number of other solutions for data collection and information distribution since the first Adherence menu. Today, Cell-Life offers a range of menu-based tools that are developed by open source consortia and support a variety of NGOs, academic institutions and civil society in managing HIV+ people across the country.

From 2003 onwards, it became apparent that one of the underestimated challenges of HIV treatment was the dispensing of medication. By 2005 only 14.9\% of South Africa's registered pharmacists were working in the public sector (Health Systems Trust 2005). To this day, pharmacies in community clinics rely heavily on paper-based systems, consisting of the patient folder, stock lists and handwritten reports. Since pharmacy management and dispensing are fundamentally very process-based and numerical tasks, it is relatively easy to transfer these particular aspects into an ICT system; on the other hand, the realities of public health care in resource constrained settings make the implementation of systems often very difficult (Brown et al. 2006). 
To address this problem, Cell-Life developed an ICT system called iDART (intelligent Dispensing of ART), which is specifically designed for ARV dispensing in the public health care sector. It was developed in an open source environment and was made available on the CellLife website.

As in the cellphone applications, the system was designed with a particular focus on the following challenges:

- the software had to support the core functions of dispensing to HIV+ patients, rather than being a fullyfledged stock management system.

- the on-site software set-up needed to be implemented within one day, and the availability of staff for training was no more than 7 hours.

- the software needed to be self-explanatory to an extent that new staff could be trained by the existing staff using the software. This was a particularly important point due to the high staff turnover.

- the software needed to be independent of internet connectivity. There was also no possibility of backing up to servers, since most of the clinics had little or no computer equipment.

- the software had to be flexible enough to allow for different dispensing models, depending on the set-up of each clinic.

The dispensing of medication in South Africa requires a registered pharmacist to be present. However, owing to the limited number of pharmacists available, most treatment sites have only one pharmacist. This results in clinics reaching a 'treatment ceiling', that is, the number of patients being able to receive treatment is physically limited. Most clinics with one pharmacist present and using a paperbased system, can dispense to approximately 80 patients per day, which results in a treatment ceiling of approximately 2000 patients for that clinic. To address this bottleneck, dispensing structures were revised and the so-called 'down-referral' model was developed. The pre-packing and down-referral model uses a pharmacist in a central location who dispenses medication, which is then sent in sealed packages to the clinic, where the patient is able to collect the medication from a pharmacy assistant. Having the package dispensed by the pharmacist, and then sent sealed to the remote 
location, enabled compliance with the existing dispensing policy since the pharmacy assistant was only required to hand the package over and dispense any additional non-prescriptive medication, such as multivitamins. However, the revised process made the tracking of medication more complex, and iDART was designed to integrate a variety of such pre-packing or down-referral models (Wood et al. 2008).

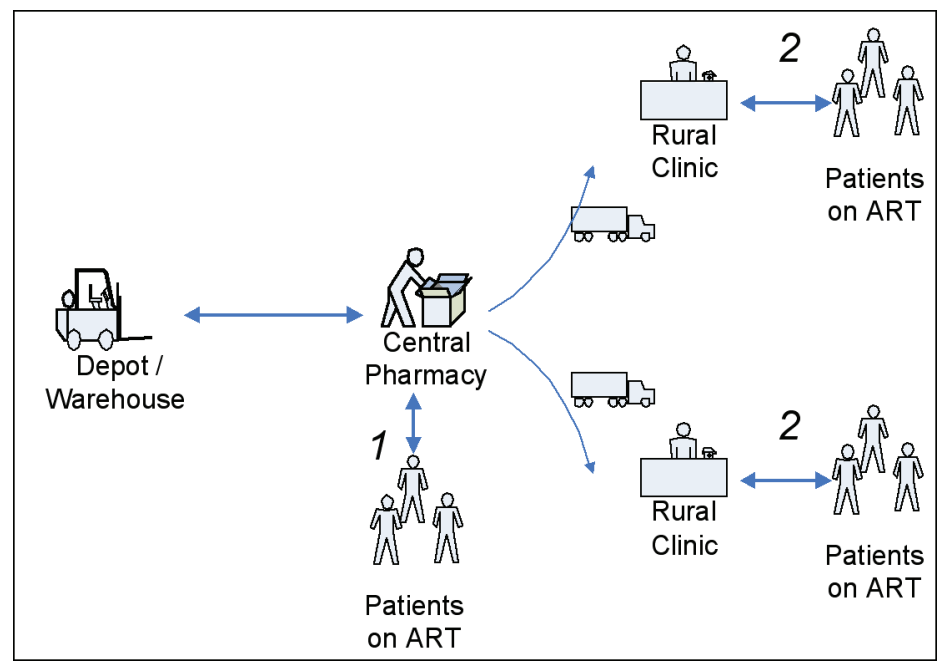

Figure 2: iDART set-up allowing for two types of ARV dispensing. Direct dispensing occurs when patients collect their medication from the pharmacy directly ( 1 in figure). Remote dispensing by down-referral occurs when patients collect their pre-packaged ARV medication from remote clinics, situated in communities ( 2 in figure). (Brown et al. 2006)

Another key challenge that had to be addressed was the backing up of patient data. Since most pharmacists had no access to the internet, GSM modems were connected to the iDART computer in each pharmacy and the patient database was backed up daily to the CellLife server using the GSM cellular network.

iDART had been developed using a process called Evolutionary Prototyping, which focuses on developing a working system by iteratively defining the requirements. This type of approach is very often used in the context where the overall system requirements are difficult to define (Carr \& Verner 1997). Due to the ever-changing environment of HIV / AIDS and thus, too, the dispensing conditions, iDART was continuously reviewed. One of the key partners of the iDART development was the Reproductive Health Research Unit (RHRU) of the University of Witwatersrand. This unit, being at the 
forefront of the newest developments in side effects, drug dispensing and other related matters, requested changes to iDART on a regular basis. The changes to the system would subsequently result in CellLife offering the updates to all other clinics, which benefitted from the knowledge of RHRU. A pharmacy assistant in a rural clinic in the North West province described iDART as 'a knowledge transfer system between universities and community clinics'.

iDART became one of the products that achieved the greatest impact for medical staff. A number of unforeseen uses of the system resulted in its benefit increasing over time. The collection of accurate patient data by the pharmacist resulted in the aggregated data required by governments or funders being produced in the pharmacy. Having patient records and the medication collection date resulted in a new way of measuring adherence; and being able to trace patients who had not collected medication resulted in a reduction in the number of patients who dropped out of an ART programme and were not recovered (in the field, such patients are know as 'loss-to-followup') (Wood et al. 2007).

iDART is today installed in more than 30 clinics across South Africa and supports ARV dispensing to nearly 70000 patients on a monthly basis.

Cell-Life spun out of the University of Cape Town and registered as a not-for-profit organisation in 2006, at a stage when the implementations of the developed technologies throughout South Africa had become the core function of the team. The organisation had to change focus and structure to move ultimately from pilot sites to the endeavour of a nationwide deployment. Research and development are to this day a key component of the organisation, but its focus lies in the implementation of technologies to support people living with HIV.

\section{DeVELOPING CELL-LIFE: ENABLERS, BARRIERS AND CHALLENGES}

Reflecting on the development of Cell-Life within an academic environment, a number of enablers, barriers and challenges can be highlighted. We have analysed these from the perspective of University management, in the sense that active steps could be taken to improve the University as an environment for socially responsive initiatives. 


\section{ENABLERS}

PARTNERSHIPS ACROSS DISCIPLINES

During 2000, in a climate of activism against the South African Government and with the need to find solutions to help people living with HIV, the University became a centre of engagement for a number of initiatives. In the case of Cell-Life, academics identified a common goal to which they were able to contribute based on their expertise within the engineering environment. Whilst Cell-Life was based in the Engineering and Built Environment Faculty, it formed very strong collaborations with colleagues in the Health Sciences, Commerce and Science Faculties. These collaborations were founded on actively sharing knowledge to identify a way to support South African communities. Partnerships and the active engagement between the various specialists were fundamental to the success of Cell-Life. Whilst the University's administrative system still reflected the understanding of research as occuring within one discipline - that is, faculty-based activity - staff members were committed to collaborate beyond these administrative borders. In many respects, the 'lowhanging fruit' - simple problems with single-solution responses have been taken care of by mainstream state and NGO organizations, and so new initiatives are aimed at complex problems, which are most likely to require cross-disciplinary solutions. A side effect of the wholesale adoption of a cost-based approach to University management is that all projects must have a host Department and Faculty for financial reasons; effectively, cross-disciplinary research is tacitly discouraged. This reinforces the natural inclination of many academics to work within vertical knowledge 'silos'. As such, an active effort by the University to encourage cross-disciplinary social responsiveness would be likely to improve the success rate in this regard.

\section{KNOWLEDGE SHARING}

Since it was the aim of Cell-Life to assist in the fight against a pandemic, all knowledge gained through the project was made available through public media and research outputs. All software that was developed was released via the open source GNU Public License (GPL), which guarantees open access to the software and the source code, and Cell-Life is still making all of its software available 
through its website. The use of open source licensing was key to generating enthusiasm from the volunteer software developers (see 'Voluntary Involvement', below). The open source licensing could have created a conflict with the University's Intellectual Property (IP) policy, under which the software should have been commercialised; however, the IP contracts manager made an ad hoc exception to the policy in this instance. This highlights the need for flexibility in University policies if successful non-traditional social responsiveness (SR) interventions are to take place. The IP policy in particular should have a formal mechanism for exempting SR initiatives from its more stringent criteria.

Pilot studies And EVAluation

Due to a number of initiatives within UCT, it was relatively easy to identify colleagues who were prepared to provide feedback on the technology developments and to support evaluation studies within their groups. Research showed that no documented evidence of similar system designs or approaches existed within the HIV sector (Sorensen et al. 2008) and the researchers therefore relied heavily on the feedback on technologies from groups such as the Desmond Tutu HIV Centre of UCT, who used the adherence cellphone application within their sites. Colleagues from the Commerce Faculty assessed the economic feasibility of some of the Cell-Life solutions, and colleagues from the Social Sciences assessed the success of the implementation in the field. The ergonomics and user-friendliness of the cellphone menu structure were assessed by colleagues from the Department of Computer Science. (Skinner et al. 2007; Hanmer et al. 2006; Nattrass et al. 2007; Kinkade \& Verclas 2008)

VOLUNTARY INVOLVEMENT

Cell-Life depended for its first three years on staff and student volunteer enthusiasm, as well as key input from some external professionals in the ICT field. It was impressive to see the level of sustained effort that could be achieved with an important goal, and that the current student body in particular has a well-developed sense of social responsiveness, which goes beyond simple or short commitments. 


\section{BARRIERS AND CHALLENGES}

TRADITIONAL RESEARCH METHODOLOGIES

New paradigms of systems design have been established through the Cell-Life initiative. Participatory Action Research (PAR) became a fundamental part of system design, and challenged the traditional approach of system design and user analysis. Whilst this can be very exciting for the researcher involved in the project, on the other hand, it brings with it the challenge of having to show the credibility of the method, and its evaluation and success by providing empirical evidence. Rather than attempting to shoehorn the evidence into an inappropriate paradigm of separation between the observer and the observed, models that acknowledge the attitude of engagement between the researcher and the community have to be developed.

PARTICIPATORY ACTION RESEARCH

Engagement with a number of stakeholders, such as community members, health workers, academics and others, results in a diverse environment which brings richness to a system design. However, it also results in the challenge of managing the various expectations and different levels of understanding. PAR is defined as a collaborative process oriented towards social transformation (McTaggart 1997); however, there is little documented information on how to manage collaborative processes which lead to creating specific system requirements that are essential for information system designs. Cell-Life experienced similar issues to the ones described by Crang (2003) regarding the challenge of communication, as well as the need to consistently reflect on the design parameters that have been developed based on the (mis)understanding between the developer and the user.

FUNDING

The Cell-Life project was not seen as traditional research, and for the first three years of Cell-Life no funding was received through the existing academic funding programmes. In particular, the state agencies responsible for funding ICT research and innovation made no contribution, despite a number of strong applications being made. The majority of income was received through donations from cellphone companies approached by the Cell-Life team. All software 
development was done by volunteers in the open source community and through student projects. This was a suitable approach for initial prototyping, but did not offer the possibility of quality assurance and support at scale.

IMPLEMENTATION AND SCALE-UP

Cell-Life implemented and evaluated its first technology solution as part of an existing research study of the Desmond Tutu HIV Centre. From 2004 onwards, a number of initiatives with organisations outside the University started; however, all of these initiatives never reached scale and stayed pilot projects. Only through the setting up of the notfor-profit organisation Cell-Life, was a focus towards implementation and roll-out created, something which had not been achieved within the University context.

It should also be noted that technology interventions tend to follow a pattern of succeeding only after several iterations, and usually in an application that was not initially envisaged. The pattern of 'serendipitous entrepreneurship' is very common. As such, one should be prepared for the first iteration of a technology solution to an SR issue to require a number of iterations prior to success, and be mentally and managerially prepared for a change in scope to provide a more useful solution.

Perceptions

The health sector in the developing world is well-used to the participation of donor-funded and civil-society programmes which tackle major health issues. Traditionally, however, all medical systems and infrastructure products are sourced from commercial, usually developed-world, vendors, and are thereafter adapted to the local need. An infrastructure provider working with an open-source, not-for-profit business model and providing very site-specific solutions requires a mind shift in administrators and managers. The uptake and success of the systems depends very strongly on the personalities and technology champions on site.

\section{Conclusions}

One of the early slogans of civil activism for treatment of HIV / AIDS was 'All of us are infected or affected by HIV / AIDS'. This rings true when considering how fighting a pandemic such as this one has a profound impact on the structure of a society. One can therefore 
reasonably argue that HIV / AIDS is more than a mere medical problem.

Cell-Life has been an initiative that has shown how infrastructure and technology development can make a substantial contribution to supporting medical staff in the endeavour of providing better care to people living with Aids.

As highlighted above, a successful rollout of ARVs does not depend only on training sufficient medical staff and providing support within communities; seemingly basic problems such as establishing infrastructure to distribute medication to patients independent of geographical location are key factors to ensure sustainable and successful lifelong treatment.

The development of technologies for the public health care sector in resource constrained settings led to approaching the user analysis and design phase in a different way to previously. Instead of identifying the lowest common denominator of users in various contexts, the team approached each site with an attitude of engagement that embedded the research within the environment of the user.

Developing software solutions for a new field requires a proof of concept, which is usually done through pilot studies. Cell-Life benefitted greatly from being able to draw on existing studies within UCT to test the first developments. Partnerships with academics and experts in the field as well as an attitude of knowledge sharing and volunteerism resulted in technologies being developed relatively quickly and at a very low cost.

A number of challenges and barriers were highlighted, such as the limitations of traditional research methods and the definition of CellLife within the academic environment. Practical considerations such as attracting funding required a creative approach away from the traditional research funding, and resulted in successfully approaching businesses in the cellphone industry to fund the first implementations and evaluations of the Cell-Life technology.

Whilst the University environment allowed the first technology developments of Cell-Life to be leapfrogged through the spirit of activism and collaboration, a focus towards providing technology solutions at a national level was only created when Cell-Life became an organisation outside of the University. There are a number of 
things that the University could do to improve the likelihood of future success. These would include:

- creating an environment which encourages crossdisciplinary solutions and eases the problem of shared finances and infrastructure.

- adapting the IP, cost recovery and contractual policies to allow for non-commercial exploitation of technology IP in the SR context.

- encouraging the recognition of research within the SR context as a valid type of scholarship, and motivating the funding agencies to provide appropriate support for this research.

The Cell-Life initiative provided an opportunity to reflect on the responsibility and relevance of research in the context of a developing country.

\section{REFERENCES}

Barnard, D 2002, 'In the High Court of South Africa, case no. 4138/98: The global politics of access to low-cost AIDS drugs in poor countries', in Kennedy Institute of Ethics Journal, vol. 12, no. 2, June 2002, pp. 159-174.

Bekker, L-G, Orrell, C, Reader, L, Matoti, K, Cohen, K, Martell, R, Abdullah, F \& Wood, R 2003, 'Anti-retroviral therapy in a community clinic: Early lessons from a pilot project', $S A$ Medical Journal, vol. 93, no. 6, pp. 458-462.

Brown, S, De Jager, D, Wood, R \& Rivett, U 2006, 'A pharmacy stock control management system to effectively monitor and manage patients on ART', The 4th Institution of Engineering and Technology Seminar on Appropriate Healthcare Technologies for Developing Countries, IET conference proceedings, London, 23-24 May.

Carr, M \& Verner, J 1997, 'Prototyping and software development approaches', Department of Information Systems, City University of Hong Kong, Hong Kong.

Crang, M 2003, 'Qualitative methods: Touchy, feely, look-see?', Progress in Human Geography, vol. 27, no. 4, pp. 494-504.

DOH 2007, 'HIV and AIDS and STI: Strategic plan for South Africa, 2007-2011', Department of Health, Pretoria.

Fynn, RW, De Jager, D, Chan, HA, Anand, S \& Rivett, U 2006, 'Remote HIV / AIDS patient monitoring tool using 3G/GPRS packet-switched mobile technology', The 4th Institution of Engineering and Technology Seminar on Appropriate Healthcare Technologies for Developing Countries, IET conference proceedings, London, 23-24 May.

Gurumurthy, A \& Singh, PJ 2009, 'ICTD - Is it a new species of development?', perspective paper, IT for Change, Bangalore, India, viewed October 2009, http:/ / www.itforchange. net/media/presentations / ICTD-Species_of_Devlp.pdf

Hanmer, LA, Dikweni, L, Ghiassi-Razavi, J, Loots, H, Minnaar, JJ \& Rivett, U 2006, 'An assessment of the effect of the use of wireless communication technology for effective management of patient care in primary health care clinics in the North West province', International Society for Telemedicine and eHealth Conference, Cape Town, November 2006. 
Heeks, R 2003, 'Success and failure rates of eGovernment in developing/transitional countries: Overview', viewed July 2009, http:/ / www.egov4dev.org/sfoverview.htm

Hirschheim, R \& Klein, HK 1989, 'Four paradigms of information systems development, Communications of the ACM, vol. 32, no. 10, pp. 1199-1216.

Health Systems Trust: Health statistics 2005 [online]: Health Personnel, http://www.hst. org.za/healthstts / 102 / data

ITU (International Telecommunication Union) 2004, 'African telecommunication indicators 2004', report prepared for Africa TELECOM, Cairo, Egypt, 4-8 May.

Kinkade, S \& Verclas, K 2008, Wireless Technology for Social Change: Trends in mobile use by NGOs, UN Foundation-Vodafone Group Foundation Partnership, Washington, DC \& Berkshire, UK.

Mbali, M 2003, 'HIV / AIDS policy-making in post-apartheid South Africa', State of the Nation: South Africa 2003-2004, Human Science Research Council, Cape Town, pp. 312-329.

McTaggart, R (ed.) 1997, Participatory action research: International context and consequences, State University of New York Press, New York.

Moodley, S 2005, 'The promise of e-development? A critical assessment of the state ICT for poverty reduction discourses in South Africa', Perspectives on Global Development and Technology, vol. 4, no. 1, pp. 1-26.

Nattrass, N 2006, What determines cross-country access to antiretroviral treatment?', Development Policy Review, vol. 24, no. 3, pp. 321-337.

Nattrass, N, Wessels, X \& Rivett, U 2007, 'Improving the efficiency of monitoring adherence to antiretroviral therapy at primary health care level: A case study of the introduction of electronic technologies in Gugulethu, South Africa', Development Southern Africa, vol. 24, no. 4, pp. 607-621.

Skinner, D, Rivett, U \& Bloomberg, C 2007, 'Evaluation of use of cell phones to aid compliance with drug therapy for HIV patients', Aids Care, vol. 19, no.5, pp. 605-607.

Sorensen, T, Rivett, U \& Fortuin, J 2008, 'Review of e-health systems for HIV/ AIDS and antiretroviral treatment management in South Africa', Journal of Telemedicine and Telecare, vol. 14, no. 1, pp. 37-41.

Wood, R, Kaplan, R, Bekker, L-G, Brown, S \& Rivett, U 2008, ‘The utility of pharmacy dispensing data for ART programme evaluation and early identification of patient loss to follow up' Southern African Journal of HIV Medicine, vol. 9, no. 2, pp. 44-48. 